\title{
COMPARISON of FUZZY-BASED MODELS in LANDSLIDE HAZARD MAPPING
}

\author{
N. Mijani ${ }^{a}$, N. Neysani Samani ${ }^{b, *}$ \\ ${ }^{a}$ MSc. Student of Remote Sensing and GIS, Department of Remote Sensing and GIS, University of Tehran, \\ Tehran, Iran - naeim.mijani@ut.ac.ir \\ ${ }^{\mathrm{b}}$ Assis. Prof of Remote Sensing and GIS, Department of Remote Sensing and GIS, University of Tehran, \\ Tehran, Iran - nneysani@ut.ac.ir
}

KEY WORDS: Landslide, Fuzzy-based Models, Quality Sum Index, Accuracy

\begin{abstract}
Landslide is one of the main geomorphic processes which effects on the development of prospect in mountainous areas and causes disastrous accidents. Landslide is an event which has different uncertain criteria such as altitude, slope, aspect, land use, vegetation density, precipitation, distance from the river and distance from the road network. This research aims to compare and evaluate different fuzzy-based models including Fuzzy Analytic Hierarchy Process (Fuzzy-AHP), Fuzzy Gamma and Fuzzy-OR. The main contribution of this paper reveals to the comprehensive criteria causing landslide hazard considering their uncertainties and comparison of different fuzzy-based models. The quantify of evaluation process are calculated by Density Ratio (DR) and Quality Sum (QS). The proposed methodology implemented in Sari, one of the city of Iran which has faced multiple landslide accidents in recent years due to the particular environmental conditions. The achieved results of accuracy assessment based on the quantifier strated that Fuzzy-AHP model has higher accuracy compared to other two models in landslide hazard zonation. Accuracy of zoning obtained from Fuzzy-AHP model is respectively 0.92 and 0.45 based on method Precision (P) and QS indicators. Based on obtained landslide hazard maps, Fuzzy-AHP, Fuzzy Gamma and Fuzzy-OR respectively cover 13, 26 and 35 percent of the study area with a very high risk level. Based on these findings, fuzzy-AHP model has been selected as the most appropriate method of zoning landslide in the city of Sari and the Fuzzygamma method with a minor difference is in the second order.
\end{abstract}

\section{INTRODUCTION}

Slope instability is one of the important natural phenomena. Increasing trend of urbanization and overuse of natural resources has exacerbated this phenomenon (Ercanoglu and Gokceoglu, 2004). Landslides are known as one the most common geological disasters which cause damages and casualties worldwide (Bianchini et al., 2016; Shahabi et al., 2014; Wang et al., 2016). The unplanned urbanization especially in developing countries and wide climate changes through global warming increase the risk of natural hazards. Landslide phenomenon is an important worldwide natural hazard and Iran is no exception (Vakhshoori and Zare, 2016).

Rapid population growth, the expansion of human settlements in mountainous areas, difficulty of predicting the time of occurrence of landslides and having numerous factors involved in this phenomenon reveals the necessity of landslide hazard zonation. Landslide is considered one of the most complicated natural phenomenon which endanger human generations (Nourani et al. 2013).

Landslides are caused due to many factors such as earthquakes, rains and rapid melting of snow (Liu et al., 2011) and are affected by factors such as topography, soil and rock type, fractures and bedding, humidity levels and human activities (Florsheim and Nichols, 2013; Liu et al., 2011). Having data related to number, area and volume of landslides is important for estimation of sensitivity (Guzzetti et al., 1999; Malamud et al., 2004), determination of risk of landslides (Cardinali et al., 2002; Reichenbach et al., 2005) and long term evaluation of slopes due to the effect of mass movements (Korup ,2005; Imaizumi and Sidle, 2007; Guzzetti et al., 2008).

Landslide susceptibility map is a helpful tool for planning and decision making in landslide hazard managements (Hong et al. 2016; Tsangaratos et al., 2015). Sensitive areas with risk potential can be identified using landslide hazard zonation and landslides or damage caused by those can be prevented to some extent by provision of appropriate strategies and management practices.

Different methods have been provided for landslide hazard zonation such as logistic regression (Atkinson and Massari 2011; Conoscenti et al. 2014), neuro-fuzzy (Tien Bui et al. 2012; Vahidnia et al. 2010), decision trees (Alkhasawneh et al. 2014; Tsangaratos and Ilia 2015) and support vector machines (Dou et al. 2015; Hong et al. 2015; Peng et al. 2014), but none of those have the necessary certainty and provided methods in most cases can be used for specific areas by consideration of necessary reformations.

In this way, it seems that fuzzy-based models could model the uncertain aspect of landslide hazard mapping. Fuzzy theory was presented by Lotfi Zadeh in 1965 includes all theories which use basic concepts of fuzzy sets or membership functions.

Lotfi Zadeh (1965) stated that membership function must be defined for determination of members in one set which means membership value exclude the exact zero and one and it is a value between these two. Zero means that it has no membership in the set and one means that it is fully a member of that set (Zadeh, 1965). Many studies have been carried out in Iran and around the world for landslide hazard zonation using fuzzy logic (Chung and Fabbri 2001; Ercanoglu and Gokceoglu, 2004; Lee 2007; Pradhan, 2010).

\footnotetext{
* Corresponding author
} 
Thiery et al., (2006) used fuzzy logic to evaluate landslide-prone areas in the northern foothills of the Alps in France and introduced the use of fuzzy logic due to the high accuracy and measurement of outputs with proper definition of fuzzy logic operators and combination of sum and $\gamma$ operators for generation of landslide map as the best combination.

(Barrile et al., 2016; Akgun et al., 2012; Pourghasemi et al., 2012) some studies used fuzzy membership function to prepare landslide hazard zonation map and introduced fuzzy Logic due to the coordination of data and also for additional flexibility of spatial analysis process as very efficient and useful method in preparation of landslide hazard mapping. Due to the fact that a large part of Iran's area is mountainous, there are many areas susceptible to mass movement occurrences and many researchers are trying to provide different methods for identification and zoning of these natural hazards (Pourghasemi et al., 2012; Ghanavati et al., 2015; Pourghasemi et al., 2016; Vakhshoori and Zare, 2016; Aghdam et al., 2017; Gheshlaghi and Feizizadeh, 2017).

Mattkan et al., (2009) used variables such as geology, pedology, altitude, slope, aspect, and distance from the river, distance from the road, distance from fault, vegetation cover and land use for landslide hazard zoning in Lajim River watershed and calculated the weight of variables affecting the extraction of fuzzy membership functions using the method of relative frequency of landslides. Their results show that Fuzzy Gamma and Fuzzy Ordered Weighted Averaging models have the lowest variation and standard deviation compared to the other models.

With respect to occurrence of numerous landslides in the city of Sari over the past years, The main contribution if this paper reveals to the comprehensive criteria causing landslide hazard considering their uncertainties and comparison of different fuzzy-based models including Fuzzy-AHP, Fuzzy Gamma and Fuzzy-OR and preparing a landslide hazard mapping for Sari city.

\section{PROPOSED METHOD}

In this study, different fuzzy operators including 'AND', 'SUM', 'PRODUCT' and 'OR' considered and the 'OR' operator is selected, because the other operators classify the target area into either very high or very low susceptible zones that are inconsistent with the physical conditions of the study area. In the case of fuzzy gamma, the success and prediction rates increase for higher gamma in such a way that 0.975 shows the best result. The increasing trend of success and prediction rates of gamma operators along with the increasing of $\gamma$ value is due to the balanced effect of 'PRODUCT' and 'SUM' operators on its equation (equation 13).

The overall methodology flowchart of the study is shown in figure 1 . The methodology consists of three Steps:

Step (1): Providing spatial database including landslide conditioning factors and historical land slide locations.

Step (2): Landslide hazard mapping using Fuzzy-AHP, FuzzyGamma and Fuzzy-OR approaches.

Step (3): Accuracy assessment of the constructed maps using $\mathrm{DR}, \mathrm{QS}$ and method $\mathrm{P}$ parameter.

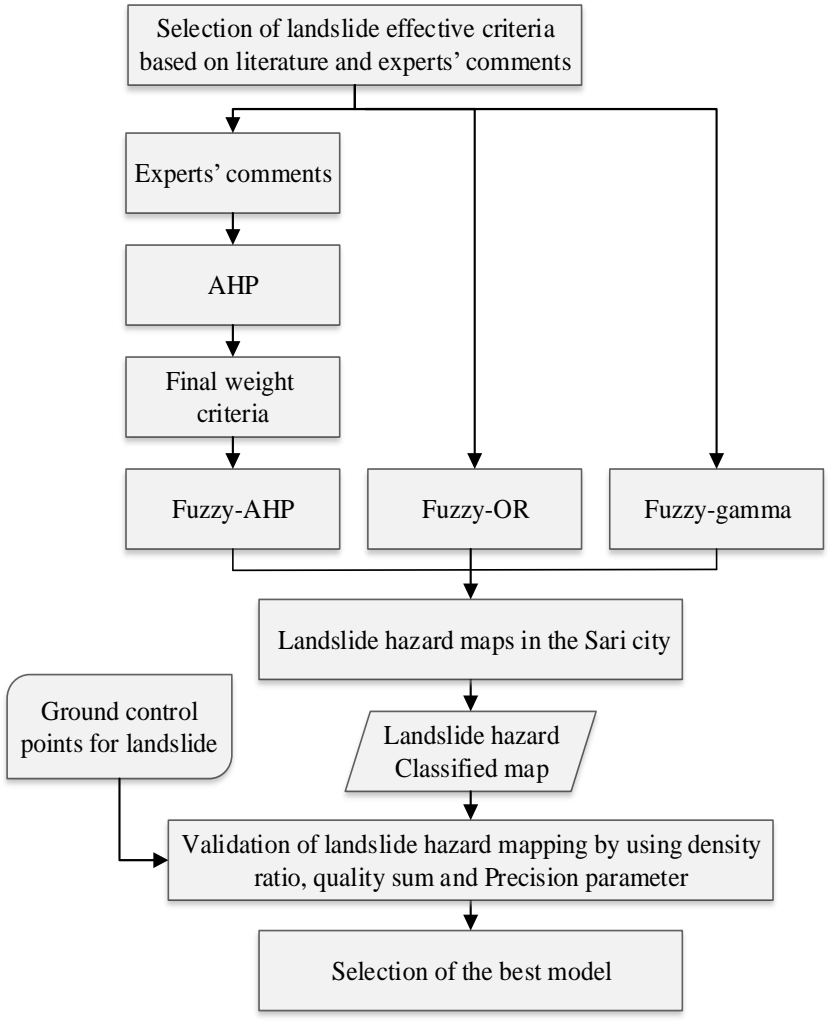

Figure 1. Flowchart of proposed methodology in the study area.

\subsection{Fuzzy logic and fuzzy-based models}

Fuzzy logic has been introduced by Zadeh (1965). Fuzzy Logic Whereas the classical theory of crisp sets can describe only the membership or non-membership of an item to a set, fuzzy logic permits partial membership, which can pose a value from 0 to 1 :

$$
\mu_{A}(x): X \rightarrow[0,1]
$$

in which $X$ refers to the universal set defined in a specific problem and $\mu_{\mathrm{A}}(\mathrm{x})$ the grade of membership for element $\mathrm{x}$ in fuzzy set A. The crisp set is a special case of fuzzy sets, in which the membership function for each element takes one of only two values: 0 or 1 (Zadeh, 1965; Samany et al., 2014). To build a fuzzy logic- based model, the proper types of membership function and its parameters should be carefully selected. The process of decomposing a given system input and/or output into fuzzy sets is called fuzzification (Samany et al., 2014). In this study, the "linear" fuzzification algorithms were used. In this study, the fuzzy logic was used for standardized factors in the range of $0-1$.

\subsection{Analytic hierarchy process (AHP)}

AHP is one of the most comprehensive methods of multi-criteria decision-making methods (Saaty, 1980) because it provides the capability of formulation of natural complex problems in hierarchy form and it can also consider different qualitative and quantitative criteria (Saaty, 1986). The greatest weight in AHP is related to a layer which has the greatest effect in determination of the objective. In other words, the criteria for weighting each information unit is also based on the greatest effect played by that factor in the layer (Malczwerski, 1999). Based on researches carried out by Saaty and Vargas (1991), a range was suggested for comparison of criteria which includes numerical values from 1 to 9 . Each of these numbers show the degree of importance in a way that 1 shows the equal importance and 9 shows the extremely strong importance of a criteria compared to another 
criteria. The AHP for weighting of criteria consists of four steps (Cay and Uyan, 2013):

1. Creation of hierarchical structure: this step is the most important step in analytic hierarchy process. Hierarchical structure is a graphical representation of a real complex problem on top of which there is the overall objective of problem and criteria, sub-criteria and alternatives are in next levels.

2. Pair-wise comparisons: this model is based on pair-wise weighting model of each one of variables with each other. A pair-wise comparison matrix $(\mathrm{n} \times \mathrm{n})$ is formed for indicators at this step. $\mathrm{i}$-th row is compared with $\mathrm{j}$-th column in pairwise comparison matrix. Hence, the values in main diagonal are equal to one and each value under the main diagonal is opposite of the value above the main diagonal

3. Preparation of normalized matrix and calculation of weight vector: in this step, the values of each one of comparison matrix columns are initially and pair wisely added to each other and them the value of each element in pairwise

4. comparison matrix is divided by the sum of values in its own column.

Then, the average of elements in each row of normalized matrix is calculated as a result of which weight vector of parameters is created.

5. Calculation of compatibility or incompatibility of weight of values: pairwise comparison matrix (A) should be initially multiplied by weight vector (C) for calculation of compatibility rate in order to obtain a good approximation of $\lambda \max$ :

$$
A \times C=\left(\begin{array}{cccc}
a_{11} & a_{12} & \ldots & a_{1 n} \\
a_{21} & a_{22} & \ldots & a_{2 n} \\
\ldots & \ldots & \ldots & \ldots \\
\ldots & \ldots & \ldots & \ldots \\
\ldots & \ldots & \ldots & \ldots \\
a_{n 1} & a_{n 2} & \ldots & a_{n n}
\end{array}\right) \times\left[\begin{array}{c}
c_{1} \\
c_{2} \\
c_{3} \\
\ldots \\
\ldots \\
c_{n}
\end{array}\right]=\left[\begin{array}{c}
x_{1} \\
x_{2} \\
x_{3} \\
\ldots \\
\ldots \\
x_{n}
\end{array}\right]
$$

Then, Consistency Index (CI) will be initially calculated as follows for measurement of compatibility rate (CR):

$$
C I=\frac{\lambda \max -n}{n-1}
$$

In this equation, $\mathrm{n}$ is the number of criterion or dimensions of $\mathrm{A}$ matrix and $\lambda \max$ is the biggest eigenvalue of $\mathrm{A}$ matrix. Then, compatibility rate is determined as follows:

$$
C R=\frac{C I}{R I}
$$

System's compatibility is acceptable if inconsistency rate is less than or equal to 0.1 and it would be better for decision maker to review the decision if it is greater than 0.1 (Khan and Samadder, 2015).

\subsection{Fuzzy AHP}

Being one of the multicriteria decision making methods, AHP enables the decision maker to regard a certain hierarchy, make association between options and make a choice. AHP has an approach that makes paired comparison of objective and nonobjective criteria, identifies the priorities among the criteria and consists of the significance of the criteria (Can and Arıkan, 2014). AHP was developed by L. T. Saaty for the first time in 1971 and it has been widely studied in literature (Saaty, 1980). Saaty has proposed the significance scale in which numbers from 1 to 9 are used while the decision maker makes paired comparison in the application process. However, most of the decisions in real life have uncertain results. In such cases, fuzzy AHP is used instead of AHP. While applying fuzzy AHP, the steps below proposed by Chang should be followed (Chang, 1996):

Step 1: $X=\left\{x_{1}, x_{2}, \ldots, x_{n}\right\}$ being criteria set and $U=\left\{u_{1}, u_{2}, \ldots\right.$, $\left.\mathrm{u}_{\mathrm{n}}\right\}$ being targets set, degree analysis $\left(\mathrm{g}_{\mathrm{i}}\right)$ is applied for every target by regarding every criterion. $\mathrm{M}$ degree analysis value related to the targets is expressed in triangular fuzzy numbers $\mathrm{M}_{\mathrm{gi}}^{1}, \mathrm{M}_{\mathrm{gi}}^{2}, \mathrm{M}_{\mathrm{gi}}^{3}$ as, $\mathrm{i}=1,2, \ldots, \mathrm{n}$ and $\mathrm{j}=1,2, \ldots, \mathrm{m}$. So, $\mathrm{M}_{\mathrm{gi}}^{\mathrm{j}}$ shows triangular fuzzy number related to $\mathrm{j}$ target according to $\mathrm{i}$ criteria. For example, $\mathrm{M}_{\mathrm{g} 1}^{2}$ is triangular fuzzy number related to target-2 according to criteria-1.

Step 2: Fuzzy synthetic degree value related to i criterion is stated as;

$$
S_{i}=\sum_{j=1}^{m} M_{g i}^{j} \otimes\left[\sum_{i=1}^{n} \sum_{j=1}^{m} M_{g i}^{j}\right]^{-1}
$$

Here, equalities are attained as triangular fuzzy number $\left(l_{i}\right.$, $\left.\mathrm{m}_{\mathrm{i}}, \mathrm{u}_{\mathrm{i}}\right)$ :

$$
\begin{aligned}
\sum_{j=1}^{m} M_{g i}^{j} & =\left(\sum_{j=1}^{m} l_{j}, \sum_{j=1}^{m} m_{j}, \sum_{j=1}^{m} u_{j}\right) \\
{\left[\sum_{i=1}^{n} \sum_{j=1}^{m} M_{g i}^{j}\right]^{-1} } & =\left(\frac{1}{\sum_{j=1}^{m} u_{j}}, \frac{1}{\sum_{j=1}^{m} m_{j}}, \frac{1}{\sum_{j=1}^{m} l_{j}}\right)
\end{aligned}
$$

Step 3: Significance vector is calculated indicated as: $\mathrm{W}=$ $\left(d\left(A_{1}\right), d\left(A_{2}\right), \ldots ., d\left(A_{n}\right)\right)^{T}$. W vector is attained by normalizing $\mathrm{W}^{\prime}$ vector. $\mathrm{i}=1,2, \ldots, \mathrm{n}$, is described as:

$$
\begin{gathered}
W^{\prime}=\left(d^{\prime}\left(A_{1}\right), d^{\prime}\left(A_{2}\right), \ldots, d^{\prime}\left(A_{n}\right)\right)^{T} \\
d^{\prime}\left(A_{i}\right)=\min V\left(S_{i} \geq S_{k}\right), k=1,2, \ldots, n \text { and } k \neq i
\end{gathered}
$$

For the triangular fuzzy numbers $\mathrm{M}_{1}=\left(\mathrm{l}_{1}, \mathrm{~m}_{1}, \mathrm{u}_{1}\right)$ and $\mathrm{M}_{2}=$ $\left(l_{2}, m_{2}, u_{2}\right)$, the numbers $M_{1}$ and $M_{2}$ should be compared calculating both, $V\left(M_{1} \geq M_{2}\right)$ and $V\left(M_{2} \geq M_{1}\right)$ values. That is why, $d^{\prime}\left(A_{i}\right)$ values are calculated according to the equality in number (9) by using the equality in number (10) in order to indicate the likelihood $\mathrm{M}_{2} \geq \mathrm{M}_{1}$ of $\mathrm{V}\left(\mathrm{M}_{2} \geq \mathrm{M}_{1}\right)$ statement.

$$
V\left(M_{2} \geq M_{1}\right)= \begin{cases}1, & m_{2} \geq m_{1} \\ 0, & l_{1} \geq u_{2} \\ \frac{\left(l_{1}-u_{1}\right)}{\left(m_{2}-u_{2}\right)-\left(m_{1}-l_{1}\right)} & \text { otherwise }\end{cases}
$$

Elements of $\mathrm{W}$ vector are calculated as:

$$
d\left(A_{i}\right)=d^{\prime}\left(A_{i}\right) /\left[d^{\prime}\left(A_{1}\right)+d^{\prime}\left(A_{2}\right)+\cdots+d^{\prime}\left(A_{n}\right)\right]
$$

$i=1,2, \ldots, n$

Here, $\mathrm{W}^{\prime}$ vector and $\mathrm{W}$ vector is found. The ultimate decision is reached suitably for the hierarchical structure of the AHP approach known with W significance vector which is not fuzzy and calculated from the comparison matrix attained by the triangular fuzzy numbers.

\subsection{Fuzzy-OR}

This operator uses the maximum function in combination and is equal to aggregation and it is calculated as (Chung and Fabbri, 2001):

$$
\mu_{O R}(x)=\operatorname{MAX}\left[\mu_{A}(x), \mu_{B}(x), \ldots, \mu_{N}(x)\right]
$$

This operator extracts the maximum degree of membership for members which means it extracts the maximum value (weight) 
of each pixel in all informational layers and provides the final map and that is why this operator considers almost the entire area in landslide hazard zonation in extreme risk class.

\subsection{Fuzzy- $\gamma$}

This operator is defined based on multiplication of algebraic fuzzy sum and multiplication and it is calculated as (Chung and Fabbri, 2001):

$$
\begin{gathered}
\mu_{\gamma}(x)=\left[\mu_{\text {SUM }}(x)\right]^{\gamma} \times\left[\mu_{\text {PRODUCT }}(x)\right]^{1-\gamma} \\
\mu_{S U M}(x)=1-\prod_{i=1}^{n} \mu_{i}(x) \quad, \quad \mu_{P R O D U C T}(x)=\prod_{i=1}^{n} \mu_{i}(x)
\end{gathered}
$$

In this equation, $\mu_{\gamma}(\mathrm{x})$ is a result of fuzzy gamma and $\gamma$ is the parameters determined in the range of zero and one. When $\gamma$ is equal to one, the applied combination is the same fuzzy algebraic sum and when $\gamma$ is equal to zero, combination is equal to fuzzy algebraic multiplication. $\gamma$ varies between zero and one. Fuzzy gamma function of 0.975 has been used in this research.

\subsection{The effective criteria}

The main data layers required for landslide hazard assessment in the study area are shown in Table 1.

\begin{tabular}{|c|c|}
\hline Criteria & Description of Criteria \\
\hline Slope & $\begin{array}{l}\text { Slope is one of the main factors causing landslides } \\
\text { in different areas. The function is straight and } \\
\text { linear for fuzzification of slope layer since } \\
\text { increases level of slope increases the risk of } \\
\text { landslides. }\end{array}$ \\
\hline Altitude & $\begin{array}{l}\text { Altitude has been introduced as one of the factors } \\
\text { affecting landslide hazard because it has an } \\
\text { important role in controlling of the degree and } \\
\text { type of erosion. The type of function for its } \\
\text { fuzzification is straight and linear since the } \\
\text { increased level of height increases the landslide } \\
\text { hazard. }\end{array}$ \\
\hline Land use & $\begin{array}{l}\text { Land uses including forest, agricultural use } \\
\text { (rainfed), irrigated agriculture and gardens, built } \\
\text { areas, bare land and water-filled areas have been } \\
\text { identified in the study area based on carried out } \\
\text { evaluations. The type of function for fuzzification } \\
\text { of land use layer is reversed and linear. }\end{array}$ \\
\hline $\begin{array}{l}\text { Vegetation } \\
\text { cover }\end{array}$ & $\begin{array}{l}\text { The type of function for fuzzification of it is } \\
\text { reversed and linear since there is a greater risk of } \\
\text { falling in areas with poor vegetation cover which } \\
\text { also have high level of slope. }\end{array}$ \\
\hline Rainfall & $\begin{array}{l}\text { Rainfall has a direct relation with landslide hazard } \\
\text { and increased rainfall increases the risk of } \\
\text { landslide by reduction of shear strength of } \\
\text { different levels. Direct linear function has been } \\
\text { used for fuzzification of rainfall map. }\end{array}$ \\
\hline $\begin{array}{l}\text { Distance } \\
\text { from the } \\
\text { road }\end{array}$ & $\begin{array}{l}\text { Construction of roads has the most important role } \\
\text { among human activities in creation of new } \\
\text { landslides and stimulation of old landslides. Non- } \\
\text { normative also is among the causes of landslides } \\
\text { in addition to road density. }\end{array}$ \\
\hline $\begin{array}{l}\text { Distance } \\
\text { from the } \\
\text { river }\end{array}$ & $\begin{array}{l}\text { The type of function for fuzzification of it is } \\
\text { reversed and linear since increased distance from } \\
\text { the river reduces the risk of landslide and as a } \\
\text { result, the score will be less. }\end{array}$ \\
\hline Aspect & $\begin{array}{l}\text { Aspect has been introduced as one of the factors } \\
\text { affecting landslide hazard. The function is straight } \\
\text { and linear for fuzzification of aspect layer. }\end{array}$ \\
\hline
\end{tabular}

Table 1. Main data layers

\subsection{Assessing the accuracy of zoning}

In this level, we match the distribution map of landslides in the area and risk zoning maps to evaluate and compare landslide hazard zonation methods using QS and P methods. DR is used for evaluation and comparison of accuracy between zones or levels of risk (Yalcin, 2008).

\subsubsection{Validation or Quality Sum (QS)}

DR is required to be initially calculated for determination of QS which is calculated as following (Gee, 1992):

$$
D R=\left(\frac{S_{i}}{A_{i}}\right) /\left(\sum_{i}^{n} S_{i} / \sum_{i}^{n} A_{i}\right)
$$

In which $S_{i}$ is the total area of landslides in each risk level, $A_{i}$ is $\mathrm{i}$-th level of risk in a zoning map and $\mathrm{n}$ is the number of risk levels.

Density of landslides risk is ascending from low levels to high levels of risk in hazard maps which have been prepared properly. A method (map) of zoning in landslides density level with DR= 1 is equal to average density of landslides in the whole area and level with DR of 2 has landslide density two times larger than landslide density of the area.

Thus, better distinction between risk levels using the indicator of DR leads to having risk better accuracy or favorability. QS which is calculated as following shows the validity or favorability of the performance of method for predicting the risk of landslide.

$$
Q S=\sum_{i=1}^{n}\left((D R-1)^{2} \times s\right)
$$

In which QS is quality sum, DR is density ration, $\mathrm{S}$ is the ratio of risk area to the total area and $\mathrm{n}$ is the number of risk classes.

Closeness of deviation of DR values from the average of different zones shows that density of landslides $n$ different classes is close to each other and the level of QS is low and high deviation of DR values from the average of different zones shows that density of landslides are different and as a result, the numerical value of QS will be large. Thus in evaluation of methods, higher value of QS in a method will lead to greater accuracy (favorability) in differentiation.

\subsubsection{Precision of method $(P)$}

It means the ration of area of landslide area in high and very high risk zones to total area of those zones which is calculated as following (Jade and Sarkar, 1993):

$$
P=K_{S} / S
$$

In which $\mathrm{P}$ is the Precision of method in zones with moderate to high risk, Ks is the area of the landslide in zones with moderate to high risk and $\mathrm{S}$ is the total area of the landslide region.

\section{CASE STUDY AREA AND REQUIRED DATA}

\subsection{Case study}

City of Sari in located in Mazandaran province of Iran. In longitude of 672590 to 764824 east and latitude of 3981925 to 4077768 north in $39^{\text {th }}$ north zone of UTM (Universal Transverse Mercator). The study area has a particular diversity in terms of climate and simultaneously has four Mediterranean semi-humid, 
wet and very wet climates. This area also has high topography changes due to being simultaneously located in mountainous and lowland environmental conditions. The study area has been shown in figure 2.

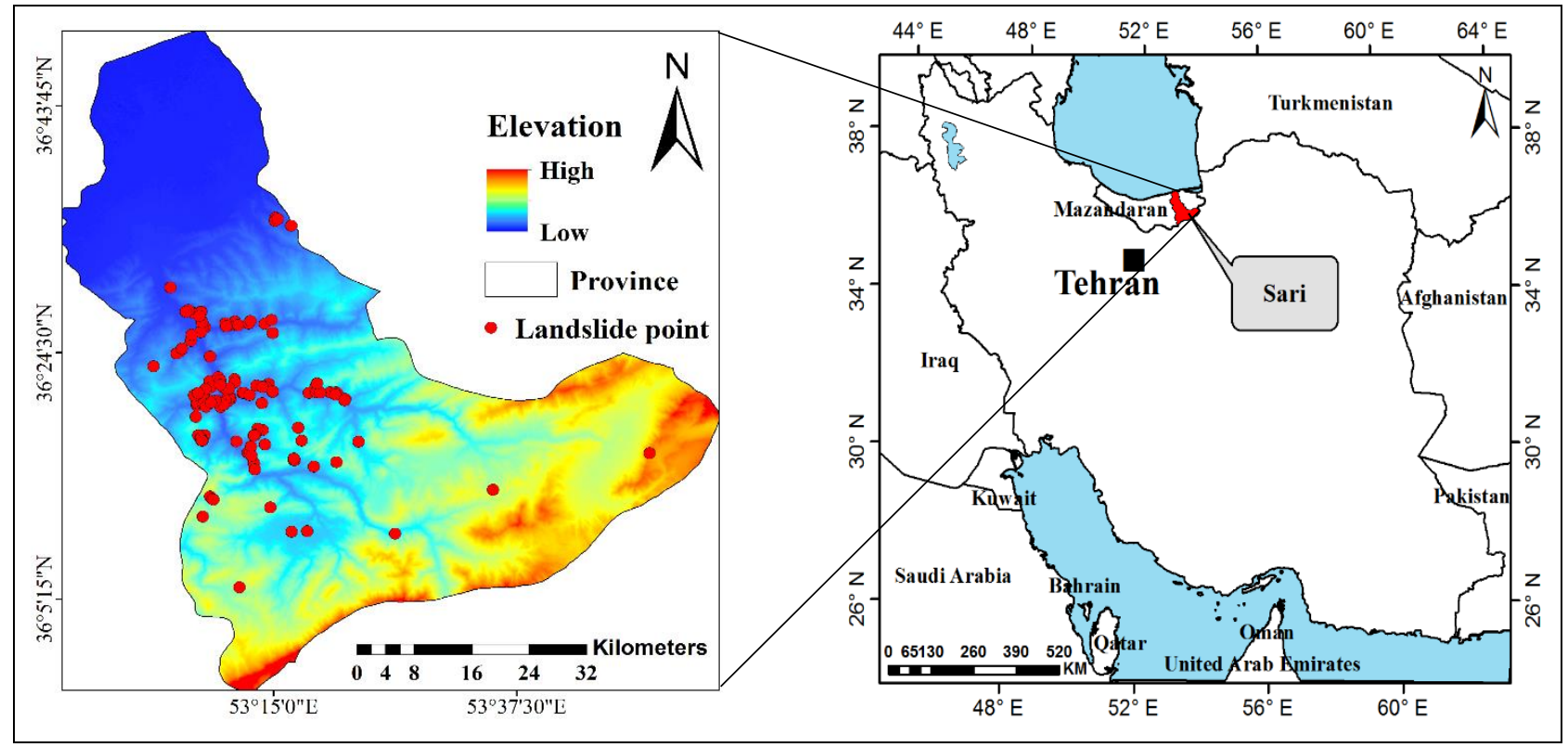

Figure 2. Location of the study area and distribution of landslide data events.

\subsection{Required data}

Initially, distribution data of landslide incidents related to the study area have been prepared from Forest, Rangeland and Watershed organization. Then, these layers were converted into landslide zones using high spatial resolution satellite imagery as well as Google Earth and 1: 100,000 geological map of Sari. This means pointed layer was converted into surface or zoning layer of landslides by determination of distribution of pointed position of landslides on mentioned information sources of area based on this position and the area of occurred landslide as well as its apparent features (cutting area, level of fallen mass, level of dependency to surface displacement of soil) is the dependent variable in the implementation of zoning models as the most important layer used in the present study. Altitude, slope and slope aspect of area were extracted from Aster digital elevation model (DEM). normalized difference vegetation index (NDVI) density of vegetation indicator and Landsat 8 satellite image related to 2015 have been used for preparation of vegetation cover variable. 1:250000 land use map prepared by land use map prepared by Forest Service organization has been used for preparation of land use layer. Shapefile map of isolited lines prepared by Meteorological Agency, Shapefile map of road networks prepared by Roads and Urban Development, Shapefile map of streams network prepared by Regional Water Authority have been used respectively for preparation of rainfall, road and waterway layers.

\section{IMPLEMENTATION AND RESULTS}

Zoning and risk mapping in this research are based on fuzzy logic. Algorithms of fuzzy functions discussed in this research are linear. The fuzzy membership function tool in ArcGIS 10.4.1 was used to derive membership functions for factors used to derive spatial suitability levels. Maps of various factors have been initially converted to fuzzy maps for landslide hazard zonation using fuzzy linear membership functions. Usage and application of each one of these two functions are done based on two parameters of midpoint and distribution parameter.

Selection of function for fuzzification is based on the nature, importance and relation of each criterion with the selected objective. Since the usage of fuzzy logic model in landslide zoning is based on the analysis of raster (grid), each pixel in each criterion must take a membership value from zero to one based on the ideal function. Fuzzy maps of criteria effective in landslides have been shown in figure 3 .
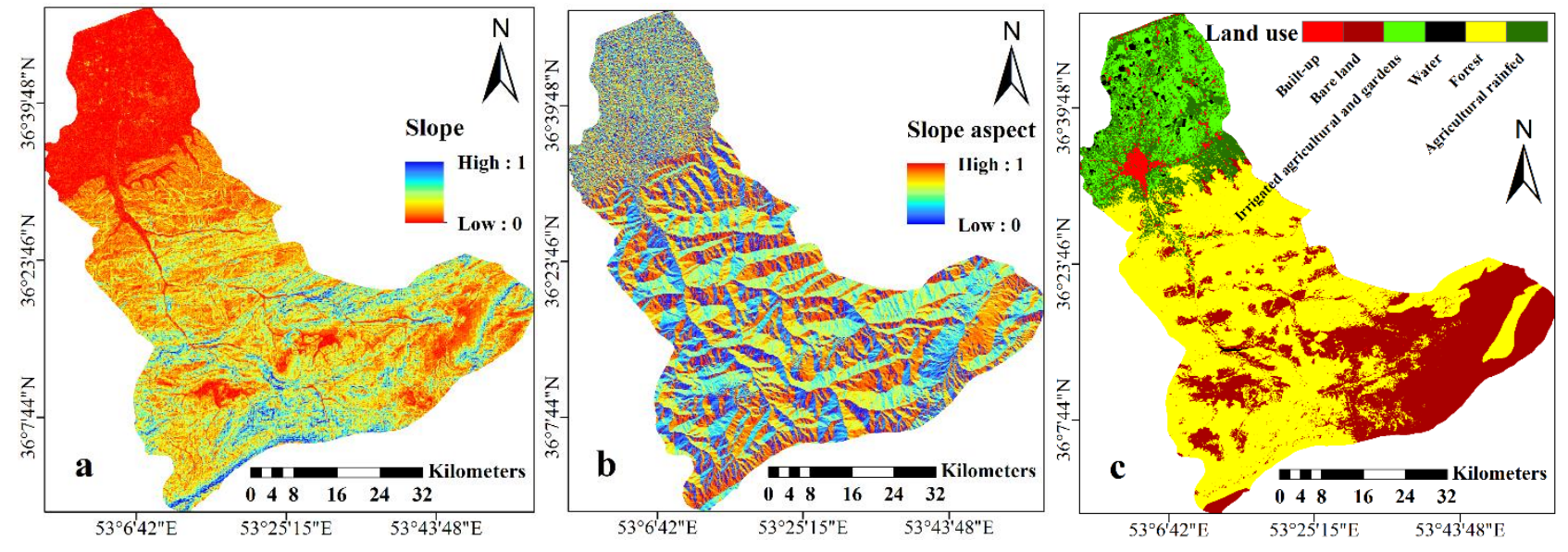


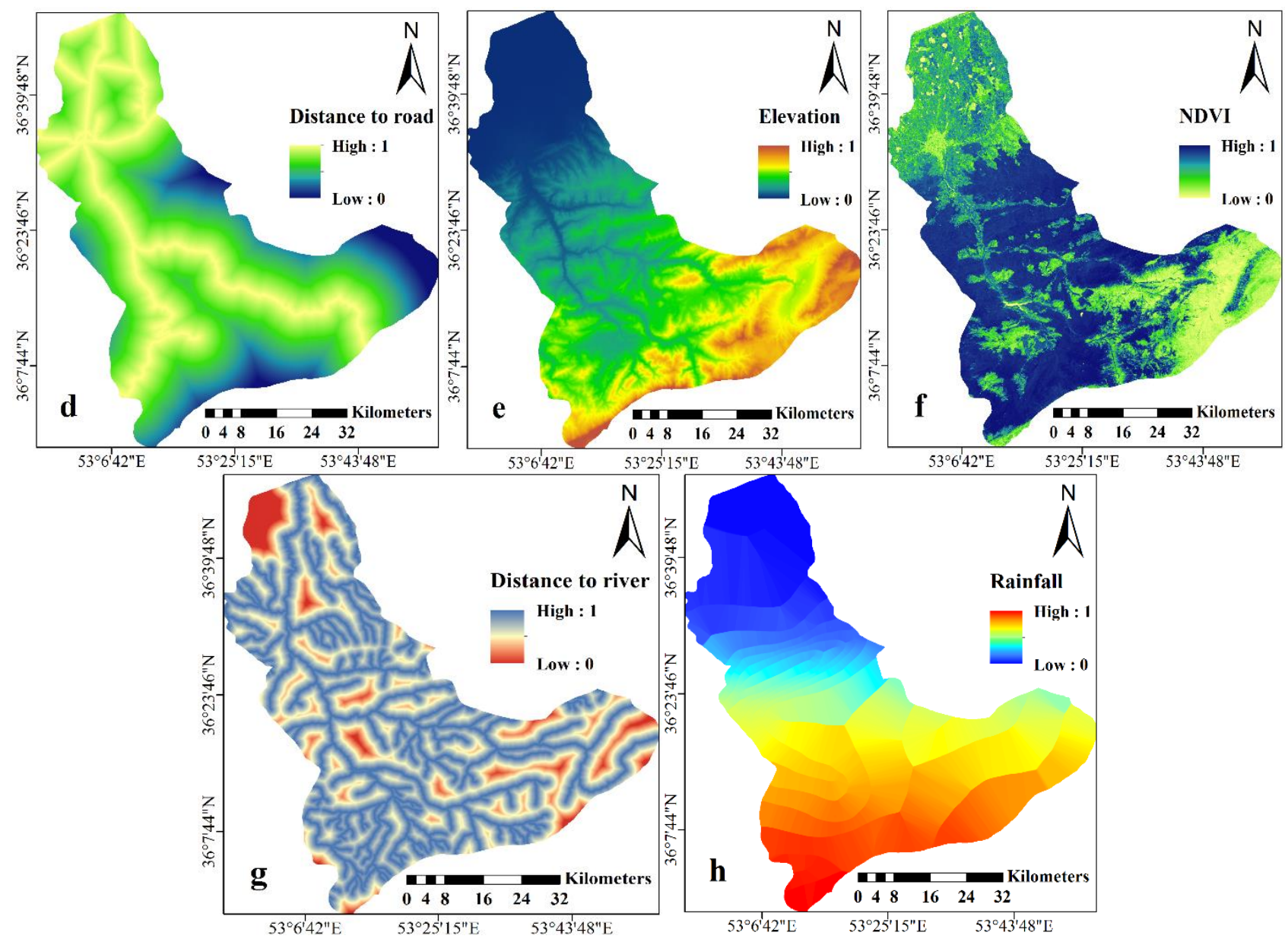

Figure 3. Landslide contributing-factor layers produced for the study area: (a) slope, (b) slope aspect, (c) land use, (d) distance to roads, (e) elevation, (f) NDVI, (g) distance to river, (h) rainfall

After defining membership functions and fuzzification of effective criteria, landslide hazard zonation maps have been overlapped using Fuzzy-AHP model and OR operators and gamma of 0.975 by overlaying the layers of effective classes on each other in landslide with Fuzzy Overlay command.

Weights of criteria in Fuzzy-AHP model have been calculated and the results are shown in form of figure 4. In the end, the landslide hazard map of Sari was prepared using each one of these operators and the results of have been shown in form of figure 5. The area of different classes of risk for Fuzzy-AHP models, gamma of 0.975 and OR operator have been calculated and their results have been shown in form of figure 6 .

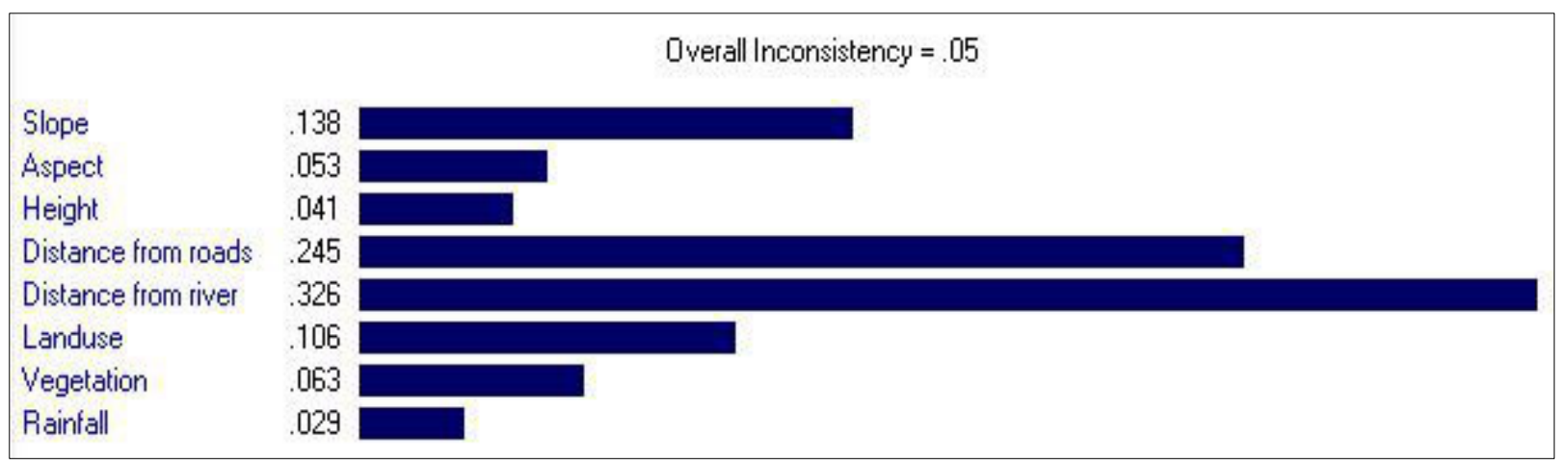

Figure 4. Weight of criteria used in Fuzzy-AHP model for preparation of landslide hazard mapping using AHP method 

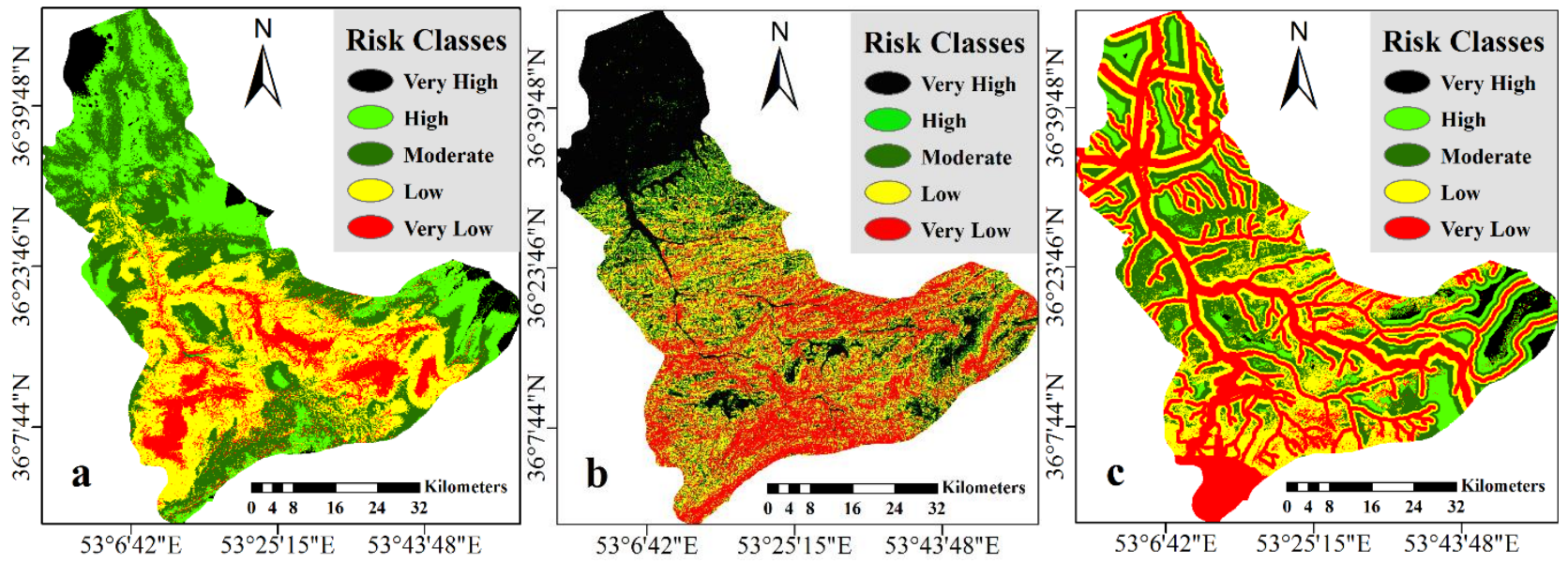

Figure 5. Landslide hazard zonation map using a) Fuzzy-AHP model b) Gamma operator of 0.975 C) OR operator

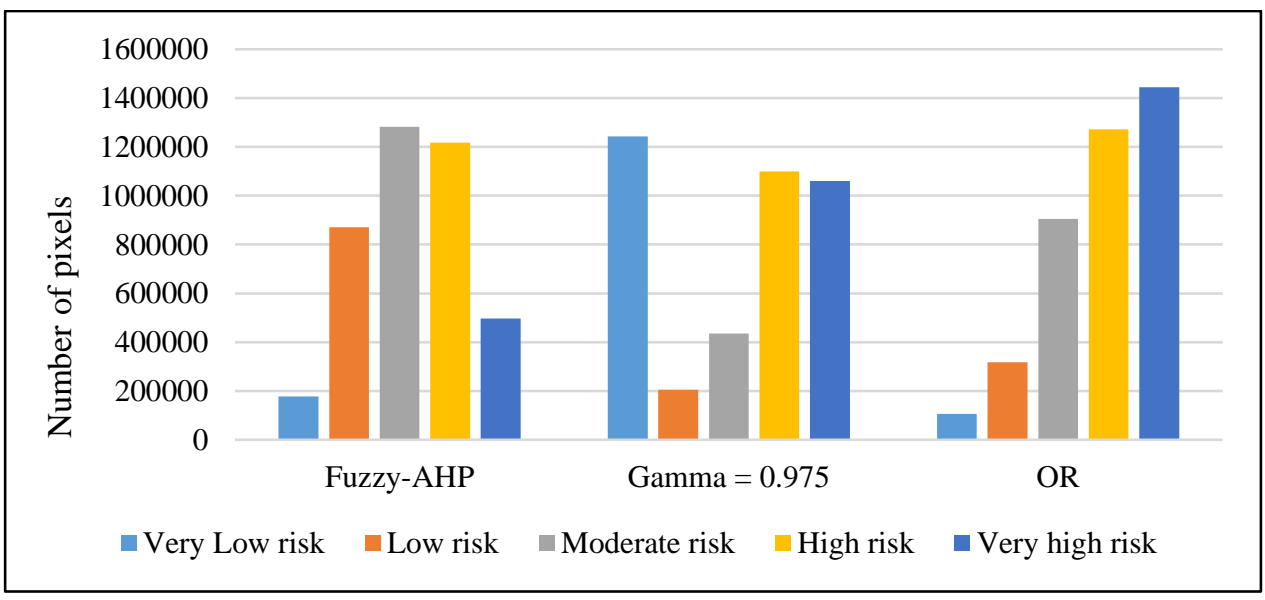

Figure 6. The area of different classes of risk for Fuzzy-AHP models, gamma of 0.975 and OR operator

Validation and accuracy of landslide hazard zonation models for Fuzzy-AHP models, gamma of 0.975 and OR operator have been evaluated using DR, QS and method P parameter quantified and the results have been depicted as tables 2 to 4 .

Table 2. Validation and accuracy of landslide hazard zonation using Fuzzy-AHP model

\begin{tabular}{|c|c|c|c|c|c|c|c|}
\hline $\begin{array}{c}\text { Precision of } \\
\text { (P) method }\end{array}$ & $\begin{array}{c}\text { Quality } \\
\text { Sum (QS) }\end{array}$ & $\begin{array}{c}\text { QS in each } \\
\text { category }\end{array}$ & $\begin{array}{c}\text { Percentage } \\
\text { of area (S) }\end{array}$ & $\begin{array}{c}\text { Density } \\
\text { Ratio (DR) }\end{array}$ & $\begin{array}{c}\text { Area of slide } \\
\text { (Pixel) }\end{array}$ & $\begin{array}{c}\text { Area of zone } \\
\text { (Pixel) }\end{array}$ & $\begin{array}{c}\text { Danger of } \\
\text { slide category }\end{array}$ \\
\hline \multirow{4}{*}{0.92} & 0.04 & 0.04 & 0 & 0 & 177547 & Very Low \\
\cline { 3 - 8 } & \multirow{3}{*}{0.45} & 0.09 & 0.22 & 0.34 & 543 & 870698 & Low \\
\cline { 3 - 8 } & & 0.05 & 0.31 & 0.59 & 1371 & 1281871 & Moderate \\
\cline { 3 - 8 } & & 0.075 & 0.3 & 1.5 & 3288 & 1216427 & High \\
\cline { 3 - 8 } & & 0.2 & 0.13 & 2.23 & 2083 & 497443 & Very High \\
\cline { 3 - 8 } & & & & 7285 & 4043986 & Sum \\
\hline
\end{tabular}

Table 3. Validation and accuracy of landslide hazard zonation using gamma operator of 0.975

\begin{tabular}{|c|c|c|c|c|c|c|c|}
\hline $\begin{array}{c}\text { Precision of } \\
\text { (P) method }\end{array}$ & $\begin{array}{c}\text { Quality } \\
\text { Sum (QS) }\end{array}$ & $\begin{array}{c}\text { QS in each } \\
\text { category }\end{array}$ & $\begin{array}{c}\text { Percentage } \\
\text { of area (S) }\end{array}$ & $\begin{array}{c}\text { Density } \\
\text { Ratio (DR) }\end{array}$ & $\begin{array}{c}\text { Area of slide } \\
\text { (Pixel) }\end{array}$ & $\begin{array}{c}\text { Area of zone } \\
\text { (Pixel) }\end{array}$ & $\begin{array}{c}\text { Danger of } \\
\text { slide category }\end{array}$ \\
\hline \multirow{4}{*}{0.78} & & 0.11 & 0.4 & 0.46 & 1041 & 1243676 & Very Low \\
\cline { 3 - 8 } & \multirow{3}{*}{0.21} & 0.01 & 0.05 & 1.48 & 549 & 204802 & Low \\
\cline { 3 - 8 } & & 0.05 & 0.2 & 1.5 & 1177 & 435605 & Moderate \\
\cline { 3 - 8 } & & 0.04 & 0.27 & 1.4 & 2761 & 1099928 & High \\
\cline { 3 - 8 } & & 0.001 & 0.26 & 0.92 & 1757 & 1059975 & Very High \\
\cline { 3 - 8 } & & & & 7285 & 4043986 & Sum \\
\hline
\end{tabular}


Table 4. Validation and accuracy of landslide hazard zonation using OR operator

\begin{tabular}{|c|c|c|c|c|c|c|c|}
\hline $\begin{array}{c}\text { Precision of } \\
\text { (P) method }\end{array}$ & $\begin{array}{c}\text { Quality } \\
\text { Sum (QS) }\end{array}$ & $\begin{array}{c}\text { QS in each } \\
\text { category }\end{array}$ & $\begin{array}{c}\text { Percentage } \\
\text { of area (S) }\end{array}$ & $\begin{array}{c}\text { Density } \\
\text { Ratio (DR) }\end{array}$ & $\begin{array}{c}\text { Area of slide } \\
\text { (Pixel) }\end{array}$ & $\begin{array}{c}\text { Area of zone } \\
\text { (Pixel) }\end{array}$ & $\begin{array}{c}\text { Danger of } \\
\text { Slide category }\end{array}$ \\
\hline \multirow{4}{*}{0.88} & & 0.018 & 0.02 & 0.04 & 9 & 106058 & Very Low \\
\cline { 3 - 8 } & & 0.012 & 0.08 & 1.4 & 799 & 316955 & Low \\
\cline { 3 - 8 } & \multirow{3}{*}{0.11} & 0.002 & 0.23 & 0.89 & 1447 & 905473 & Moderate \\
\cline { 3 - 8 } & & 0.04 & 0.32 & 0.63 & 1457 & 1271074 & High \\
\cline { 3 - 8 } & & 0.04 & 0.35 & 1.37 & 3573 & 1444426 & Very High \\
\cline { 3 - 8 } & & & & & 7285 & 4043986 & Sum \\
\hline
\end{tabular}

\section{DISSCUSION}

Hazard zonation map using Fuzzy-AHP model shows that the number of pixels in very high risk classes in terms of landslides in the study area is 497443 which is equal to $13 \%$ of total area. Landslides with high risk levels have high risk which is $30 \%$ of the area. Each class has the moderate risk of 1281871 pixels which is $31 \%$ of area. Sliding pixels of classes with low risk and very low risk are respectively 870698 and 177547 pixels which are equal to $22 \%$ and $4 \%$ of the area (Table 2). The number of sliding pixels of classes with very high risk, high risk, moderate risk, low risk and very low risk are respectively 1059975 , 1099928, 435605, 204802 and 124,676 pixels in 1059975, $1099928,435605,204802$ and 1243676 with gamma of 0.975 (Table 3). And finally, the number of same pixels for zoning map with the OR operator, are respectively, 1444426, 1271074, 905473, 316955 and 106058 pixels (Table 4).

The results of indicators of QS and method P show that DR of all three used methods are proportionate to increased risk of growing zones in addition to good resolution. Level of QS index which shows comparison and evaluation of methods in comparison with each other has been obtained to be respectively $0.45,0.21$ and 0.11 for Fuzzy- AHP, gamma of 0.975 and OR. The values of method's P are also respectively $0.92,0.78$ and 0.88 for three used operators.

\section{CONCLUSION}

Various methods and many causative factors can be used for landslide hazard mapping production depending on the scale and scope of the study. Comparison of the results of different methods in the same conditions is helpful for assessment of the relative reliability of them, although the reliability of methods is often dissimilar in different conditions.

In this study, Fuzzy-AHP, Fuzzy Gamma and Fuzzy-OR methods were compared at a regional scale, on the city of sari, in the north of Iran considering 8 causative factors. Occurrence of landslides and damages caused by those have become wider and more extensive due to increasing continuation of human changes in nature and use of mountainous areas prone to landslides. Sari has always faced many landslides due to landslides and land use changes. In this research, the validation and accuracy of different landslide hazard zonation have been evaluated and landslide hazard zoning has taken place using landslide distribution map and different algorithms. The results show that using fuzzy-based model is very effective and convenient in reducing and increasing the accuracy of landslide zoning. Also it was determined that the map of fuzzy-AHP model, OR operator and gamma of 0.975 has a high accuracy in landslide hazard zonation. Even though almost the same values were obtained for methods based on method's P which shows the almost the same and there is no limit for intervention of parameters.

Differences in validation and accuracy expresses the priority of method can be caused by things like this: inherent nature of parameters or affecting factors are different in various models and a method which is capable of comparing the priority of effective factors and their weights have greater accuracy and in other words, it will have better compliance with the potential of occurrence of landslides. Hazard zonation map with fuzzy-AHP model shows that the number of pixels in very high risk classes in terms of landslides in the study area is 497443 which is equal to $13 \%$ of total area. QS values have been obtained to be respectively $0.45,0.21$ and 0.11 for fuzzy- AHP, gamma of 0.975 and OR. Values of $P$ are also respectively $0.92,0.78$ and 0.88 for three used operators. Based on these findings, fuzzy-AHP model has been selected as the most appropriate method of zoning landslide in the city of Sari and the Fuzzy-gamma method with a minor difference is in the second order.

Nevertheless, in this study landslide hazard mapping produced in a regional scale (small-scale map), and further studies are needed in the landslide hazard mapping production for the slope stability and land use management projects in the larger-scales. Also, more studies for comparing the reliability of other methods in small-scale might be helpful.

\section{REFERENCES}

Aghdam, I. N., Pradhan, B., \& Panahi, M. 2017. Landslide susceptibility assessment using a novel hybrid model of statistical bivariate methods (FR and WOE) and adaptive neurofuzzy inference system (ANFIS) at southern Zagros Mountains in Iran. Environmental Earth Sciences, 76(6), pp. 237.

Akgun, A., Sezer, E. A., Nefeslioglu, H. A., Gokceoglu, C., \& Pradhan, B. 2012. An easy-to-use MATLAB program (MamLand) for the assessment of landslide susceptibility using a Mamdani fuzzy algorithm. Computers \& Geosciences, 38(1), pp. 23-34.

Althuwaynee, O. F., Pradhan, B., Park, H. J., \& Lee, J. H. 2014. A novel ensemble bivariate statistical evidential belief function with knowledge-based analytical hierarchy process and multivariate statistical logistic regression for landslide susceptibility mapping. Catena, 114, pp. 21-36.

Atkinson, P. M., \& Massari, R. 2011. Autologistic modelling of susceptibility to landsliding in the Central Apennines, Italy. Geomorphology, 130(1), pp. 55-64.

Barrile, V., Cirianni, F., Leonardi, G., \& Palamara, R. 2016. A Fuzzy-based Methodology for Landslide Susceptibility Mapping. Procedia-Social and Behavioral Sciences, 223, pp. 896-902.

Bianchini, S., Raspini, F., Ciampalini, A., Lagomarsino, D., Bianchi, M., Bellotti, F., \& Casagli, N. 2016. Mapping landslide phenomena in landlocked developing countries by means of satellite remote sensing data: the case of Dilijan (Armenia) area. Geomatics, Natural Hazards and Risk, pp. 1-17. 
Bui, D. T., Pradhan, B., Lofman, O., Revhaug, I., \& Dick, O. B. 2012. Landslide susceptibility mapping at Hoa Binh province (Vietnam) using an adaptive neuro-fuzzy inference system and GIS. Computers \& Geosciences, 45, pp. 199-211.

Can, S., \& Arıkan, F. 2014. Bir savunma sanayi firmasında çok kriterli alt yükleniciseçim problemi ve çözümü. Journal of The Faculty of Engineering and Architecture of Gazi University, Cilt 29(4), pp. 645-654.

Cardinali, M., Reichenbach, P., Guzzetti, F., Ardizzone, F., Antonini, G., Galli, M., ... \& Salvati, P. 2002. A geomorphological approach to the estimation of landslide hazards and risks in Umbria, Central Italy. Natural hazards and earth system science, 2(1/2), pp. 57-72.

Cay, T., \& Uyan, M. 2013. Evaluation of reallocation criteria in land consolidation studies using the Analytic Hierarchy Process (AHP). Land Use Policy, 30(1), pp. 541-548.

Chang, D. Y. 1996. Applications of the extent analysis method on fuzzy AHP. European journal of operational research, 95(3), pp. 649-655.

Chung, C. F., \& Fabbri, A. G. 2001. Prediction models for landslide hazard zonation using a fuzzy set approach. Geomorphology and Environmental Impact Assessment Balkema, Lisse, The Netherlands, pp. 31-47.

Conoscenti, C., Angileri, S., Cappadonia, C., Rotigliano, E., Agnesi, V., \& Märker, M. 2014. Gully erosion susceptibility assessment by means of GIS-based logistic regression: a case of Sicily (Italy). Geomorphology, 204, pp. 399-411.

Dou, J., Yamagishi, H., Pourghasemi, H. R., Yunus, A. P., Song, X., Xu, Y., \& Zhu, Z. 2015. An integrated artificial neural network model for the landslide susceptibility assessment of Osado Island, Japan. Natural Hazards, 78(3), pp. 1749-1776.

Ercanoglu, M., \& Gokceoglu, C. 2004. Use of fuzzy relations to produce landslide susceptibility map of a landslide prone area (West Black Sea Region, Turkey). Engineering Geology, 75(3), pp. 229-250.

Florsheim, J. L., \& Nichols, A. 2013. Landslide area probability density function statistics to assess historical landslide magnitude and frequency in coastal California. Catena, 109, pp. 129-138.

Gee, M.D., 1992. Classification of Landslides Hazard Zonation Methods and a Test of Predictive Capability. In: Bell, Davi, H. (eds.), Proceedings 6th International Symposium on Landslide, pp. 48-56.

Ghanavati, E., Karam, A., \& Taghavi, M. E. 2015. Fuzzy logic application in identifying and mapping of landslide hazard: Case study: Taleghan watershed.

Gheshlaghi, H. A., \& Feizizadeh, B. 2017. An integrated approach of analytical network process and fuzzy based spatial decision making systems applied to landslide risk mapping. Journal of African Earth Sciences.

Guzzetti, F., Ardizzone, F., Cardinali, M., Galli, M., Reichenbach, P., Rossi, M. 2008. Distribution of landslides in the Upper Tiber River basin, central Italy. Geomorphology 96, pp. 105-122.
Guzzetti, F., Carrara, A., Cardinali, M., Reichenbach, P. 1999. Landslide hazard evaluation: a review of current techniques and their application in a multi-scale study. Geomorphology, 31, pp. 181-216.

Hong, H., Chen, W., Xu, C., Youssef, A. M., Pradhan, B., \& Tien Bui, D. 2016. Rainfall-induced landslide susceptibility assessment at the Chongren area (China) using frequency ratio, certainty factor, and index of entropy. Geocarto International, 32(2), pp. 139-154.

Hong, H., Pradhan, B., Xu, C., \& Bui, D. T. 2015. Spatial prediction of landslide hazard at the Yihuang area (China) using two-class kernel logistic regression, alternating decision tree and support vector machines. Catena, 133, pp. 266-281.

Imaizumi, F., \& Sidle, R. C. 2007. Linkage of sediment supply and transport processes in Miyagawa Dam catchment, Japan. Journal of Geophysical Research: Earth Surface, 112(F3).

Jade, S., \& Sarkar, S. 1993. Statistical models for slope instability classification. Engineering Geology, 36(1-2), pp. 91-98.

Khan, D., \& Samadder, S. R. 2015. A simplified multi-criteria evaluation model for landfill site ranking and selection based on AHP and GIS. Journal of Environmental Engineering and Landscape Management, 23(4), pp. 267-278.

Korup, O. 2005. Geomorphic imprint of landslides on alpine river systems, southwest New Zealand. Earth Surface Processes and Landforms, 30(7), pp. 783-800.

Lee, S. 2007. Application and verification of fuzzy algebraic operators to landslide susceptibility mapping. Environmental Geology, 52(4), pp. 615-623.

Liu, J. P., Zeng, Z. P., Liu, H. Q., \& Wang, H. B. 2011. A rough set approach to analyze factors affecting landslide incidence. Computers \& geosciences, 37(9), pp. 1311-1317.

Malczewski, J. 1999. GIS and multicriteria decision analysis. John Wiley \& Sons.

Mttkan, A. A., Sameia, J., Pourali, S.H \& Safaei, V.M. 2009. Fuzzy logic models and remote sensing techniques for landslide hazard mapping in the watershed Lajim, Journal of Applied Geology, 5(4), pp. 318-325 (in persion).

Nourani, V., Pradhan, B., Ghaffari, H., \& Sharifi, S. S. 2013. Landslide susceptibility mapping at Zonouz Plain, Iran using genetic programming and comparison with frequency ratio, logistic regression, and artificial neural network models. Natural hazards, 71(1), pp. 523-547.

Peng, L., Niu, R., Huang, B., Wu, X., Zhao, Y., \& Ye, R. 2014. Landslide susceptibility mapping based on rough set theory and support vector machines: A case of the Three Gorges area, China. Geomorphology, 204, pp. 287-301.

Pourghasemi, H. R., Beheshtirad, M., \& Pradhan, B. 2016. A comparative assessment of prediction capabilities of modified analytical hierarchy process (M-AHP) and Mamdani fuzzy logic models using Netcad-GIS for forest fire susceptibility mapping. Geomatics, Natural Hazards and Risk, 7(2), pp. 861-885.

Pourghasemi, H. R., Pradhan, B., \& Gokceoglu, C. 2012. Application of fuzzy logic and analytical hierarchy process (AHP) to landslide susceptibility mapping at Haraz watershed, Iran. Natural hazards, 63(2), pp. 965-996. 
Pradhan, B., \& Lee, S. 2010. Landslide susceptibility assessment and factor effect analysis: backpropagation artificial neural networks and their comparison with frequency ratio and bivariate logistic regression modelling. Environmental Modelling \& Software, 25(6), pp. 747-759.

Reichenbach, P., Galli, M., Cardinali, M., Guzzetti, F., \& Ardizzone, F. 2005. Geomorphological mapping to assess landslide risk: Concepts, methods and applications in the Umbria region of central Italy. Landslide Hazard Risk, pp. 429-468.

Roering, J. J., Kirchner, J. W., \& Dietrich, W. E. 2005. Characterizing structural and lithologic controls on deep-seated landsliding: Implications for topographic relief and landscape evolution in the Oregon Coast Range, USA. Geological Society of America Bulletin, 117(5-6), pp. 654-668.

Saaty, T. L. 1980. The Analytical Hierarchy Process, Planning, Priority. Resource Allocation. RWS Publications, USA.

Saaty, T. L. 1986. Axiomatic foundation of the analytic hierarchy process. Management science, 32(7), pp. 841-855.

Samany, N. N., Delavar, M. R., Chrisman, N., \& Malek, M. R. 2014. FIA 5: A customized Fuzzy Interval Algebra for modeling spatial relevancy in urban context-aware systems. Engineering Applications of Artificial Intelligence, 33, pp. 116-126.

Shahabi, H., Khezri, S., Ahmad, B. B., \& Hashim, M. 2014. Landslide susceptibility mapping at central Zab basin, Iran: A comparison between analytical hierarchy process, frequency ratio and logistic regression models. Catena, 115, pp. 55-70.

T.L. Saaty, and L. G. Vargas. 1991 "Prediction, projection and forecasting," Kluwer Academic Publichers, Dordrecht.
Thiery, Y., Malet, J. P., \& Maquaire, O. 2006. Test of fuzzy logic rules for landslide susceptibility assessment. In SAGEO 2006: Information Géographique: observation et localisation, structuration et analyse, representation, pp. 16-p.

Tsangaratos P, Constantinos L, Dimitrios R, Ioanna I. 2015. Landslide susceptibility assessments using the k-nearest neighbor algorithm and expert knowledge. Case study of the basin of Selinounda river, Achaia County, Greece.

Tsangaratos, P., \& Ilia, I. 2016. Landslide susceptibility mapping using a modified decision tree classifier in the Xanthi Perfection, Greece. Landslides, 13(2), pp. 305-320.

Vahidnia, M. H., Alesheikh, A. A., Alimohammadi, A., \& Hosseinali, F. 2010. A GIS-based neuro-fuzzy procedure for integrating knowledge and data in landslide susceptibility mapping. Computers \& Geosciences, 36(9), pp. 1101-1114.

Vakhshoori, V., \& Zare, M. 2016. Landslide susceptibility mapping by comparing weight of evidence, fuzzy logic, and frequency ratio methods. Geomatics, Natural Hazards and Risk, 7(5), pp. 1731-1752.

Wang, L.-J., Guo, M., Sawada, K., Lin, J., Zhang, J. 2016. A comparative study of landslide susceptibility maps using logistic regression, frequency ratio, decision tree, weights of evidence and artificial neural network. Geosci. J. 20, pp. 117-136.

Yalcin, A. 2008. GIS-based Landslide Susceptibility Mapping Using Analytical Hierarchy Process and Bivariate Statistics in Ardesen (Turkey), Comparisons of results and confirmations. Catena, 72, pp. 1-12.

Zadeh, L. A. 1965. Fuzzy sets. Information and control, 8(3), pp. 338-353. 